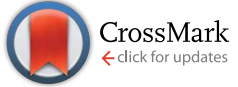

Cite this: RSC Adv., 2017, 7, 14254

Received 7th February 2017

Accepted 24th February 2017

DOI: 10.1039/c7ra01571b

rsc.li/rsc-advances

\section{Surface characteristics influencing bacterial adhesion to polymeric substrates $\uparrow$}

\author{
Yue Yuan, ${ }^{a}$ Michael P. Hays, ${ }^{\text {b }}$ Philip R. Hardwidge ${ }^{\mathrm{b}}$ and Jooyoun Kim ${ }^{\star a c}$
}

Superhydrophobic surfaces have been reported to reduce bacterial adhesion, but interactions between bacterial media and solid surfaces at the interface have rarely been associated with the solid area fraction ( $f$ ) from the Cassie-Baxter wetting state. This study aimed to investigate the effective surface area for bacterial adhesion by analyzing the solid area fraction of surfaces where the bacterial medium is in contact with a solid surface. Also, the self-cleaning ability of the superhydrophobic surface against adhered bacteria was examined. The influences of roughness, surface energy, entrapped air, and surface charge of substrate materials on bacterial adhesion were examined, and the critical surface characteristics that are conducive to reducing Escherichia coli adherence to polymeric surfaces were determined. Moderate hydrophobicity with water contact angle of about $90^{\circ}$ produced the highest level of bacterial adhesion. Entrapped air at the interface of superhydrophobic surfaces interfered with the direct contact of bacteria to solid surfaces, leading to less bacterial adhesion. The superhydrophobic surface with a reduced solid area fraction displayed self-cleaning ability, where initially-adhered bacteria were removed by washing. The superhydrophilic substrate with negative zeta potential exhibited limited bacterial binding, due to the reduced hydrophobic interaction and possible repulsive interaction between bacteria and surface. The findings of this study can be utilized for an effective surface design to circumvent bacterial adhesion as an alternative solution to using antibiotics.

\section{Introduction}

Bacterial adhesion and subsequent biofilm formation on surfaces can limit material applications and increase health risks and costs. As the use of antibiotics can aggravate biofilm formation, ${ }^{\mathbf{1 - 3}}$ material design that limits bacterial adhesion to surfaces has been explored as an alternative method of using biocides to kill bacteria directly. ${ }^{4-9}$ For an effective surface design to resist bacterial adhesion, multiple aspects of material properties need to be considered, including surface energy, wettability, ${ }^{10-14}$ surface charges, ${ }^{3,15}$ and material topography..$^{5-7,16-19}$ In general, surfaces with moderate wettability are more able to bind bacteria or cells, as compared with extremely hydrophobic or hydrophilic surfaces. ${ }^{3,20}$ Lee et al. ${ }^{21}$ reported that surface with water contact angles (CA) of $40-70^{\circ}$ enhanced cell adhesion and growth, while Dou et al. ${ }^{13}$ showed that surfaces with CA of $54-130^{\circ}$ had a higher adsorption of bacterial peptidoglycan. A hydrophobic material with surface energy of 20-30

${ }^{a}$ Department of Apparel, Textiles, and Interior Design, Kansas State University, Manhattan, Kansas 66506, USA.E-mail: jkim256@ksu.edu

${ }^{b}$ Department of Diagnostic Medicine and Pathobiology, Kansas State University, Manhattan, Kansas 66506, USA

'Johnson Cancer Research Center, Kansas State University, Manhattan, Kansas 66506, USA

$\dagger$ Electronic supplementary information (ESI) available. See DOI: 10.1039/c7ra01571b
$\mathrm{mN} \mathrm{m}^{-1}$ (ref. 3, 10 and 11) produced lower bacterial adhesion, as compared to materials with higher surface energies. Harnett et al. ${ }^{12}$ reported that the polar component of the surface energy is important for cell adhesion and spreading, where the polar component lower than $5 \mathrm{mN} \mathrm{m}^{-1}$ led to reduced cell spreading and that greater than $15 \mathrm{mN} \mathrm{m}^{-1}$ promoted spreading. ${ }^{12}$

The effect of surface topography on bacterial adhesion and biofilm formation has been extensively studied..$^{5-7,16-19}$ While a large surface area with rough topography can promote bacterial adhesion, topographic patterns that are favorable for bacterial adhesion cannot be generalized, since the shape and size of bacteria also play roles in bacterial interactions with material surfaces. Therefore, the spatial distribution of roughening structures and macroscopic/microscopic patterns on surfaces, relative to bacterial size and shape, are important parameters for bacterial adhesion..$^{5-7,16-19}$

Superhydrophobic surfaces with extremely low wettability $\left(\mathrm{CA}>150^{\circ}\right)$ have been examined for their ability to resist bacterial adhesion. ${ }^{3,8,22-25}$ A superhydrophobic surface can be fabricated by implementing roughness to a low surface energy surface, and because of this roughness, air becomes entrapped between roughening features when a liquid is in contact with the solid surface. ${ }^{26-30}$ The maintenance of entrapped air plays an important role in suppressing bacteria adhesion ${ }^{22}$ by reducing the contact area at the interface and decreasing the adhesion force. However, if entrapped air is intruded by bacterial media, 


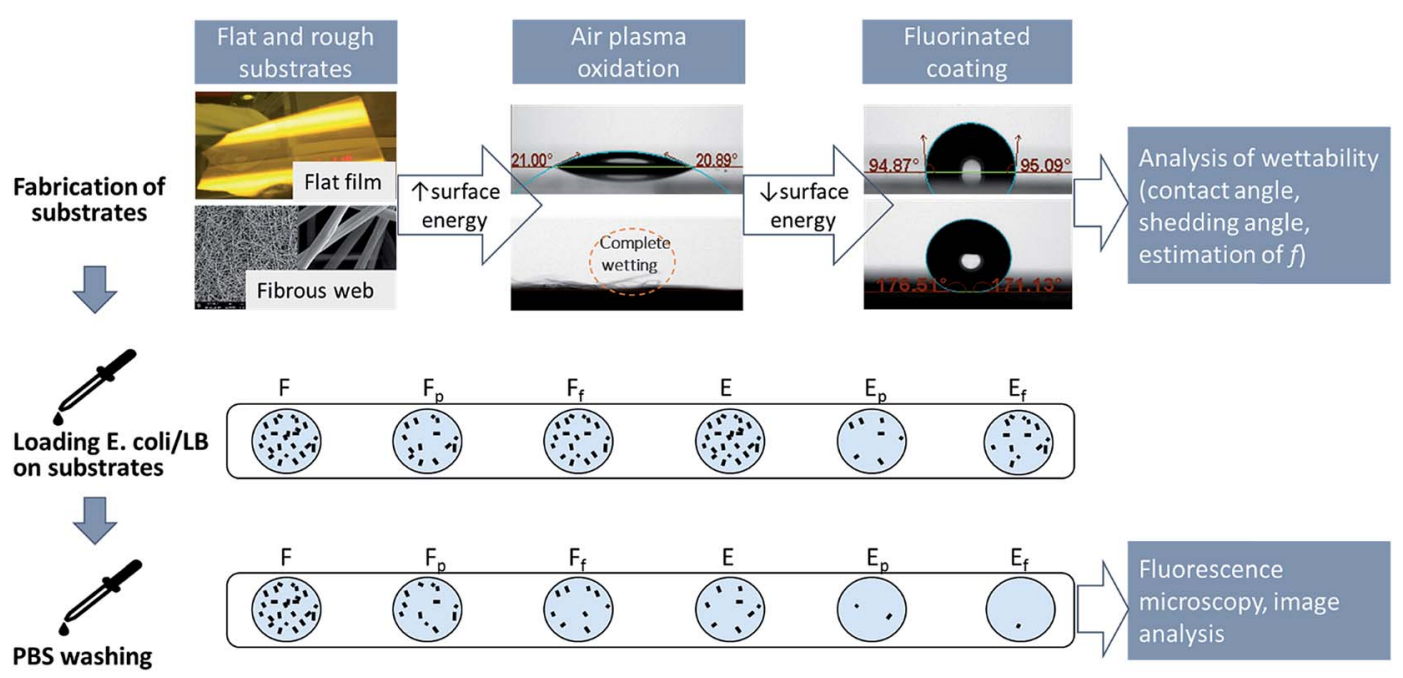

Fig. 1 Research approach schematic.

the roughness then provides a larger surface area to adhere more bacteria, eventually promoting bacterial growth. ${ }^{13,31-33}$ Thus, to clarify the influence of surface roughness on bacterial adhesion, the solid area fraction $(f)$ of the Cassie-Baxter model, ${ }^{34}$ where the liquid is in contact with solid as opposed to air, needs to be analyzed. It is also worthwhile to examine the self-cleaning ability of a superhydrophobic surface attributed to the reduced $f$, in relation to bacterial removal with wash procedures.

The purpose of this study is to investigate the influence of effective surface area for bacterial contact, estimated by the solid area fraction $(f)$, on initial bacterial binding and selfcleaning ability against adhered bacteria. The critical surface characteristics that are conducive to reducing Escherichia coli adherence to polymeric surfaces were examined for surface area, surface energy, entrapped air, and material surface charge. Polystyrene (PS) substrates of differing wettability were produced by modifying the surface energy and roughness of PS surfaces. The modified substrates were tested for the initial adherence of enterotoxigenic Escherichia coli (ETEC) and the amount of $E$. coli that remained adherent after washing. The overall research approach is illustrated in Fig. 1.

\section{Materials and methods}

\section{Materials}

Polystyrene (PS) pellets ( $\left.M_{\mathrm{w}} 192000,>99 \%\right)$ were purchased from Sigma-Aldrich (USA). 1H,1H,2H,2H-Perfluorodecyltrichlorosilane (PFDTS) (96\%) was purchased from Alfa Aesar (USA). Solvents including $N, N$-dimethylformamide (DMF), tetrahydrofuran (THF), methylene iodide (MI), acetone, isopropanol, and toluene were purchased from Sigma-Aldrich (USA). $n$-Hexane was purchased from Fisher Scientific (USA). Escherichia coli strain 3030-2 expressing the green fluorescence protein (GFP) was used in adherence assays. LB Miller Broth and phosphate buffered saline (PBS) were obtained from MIDSCI (USA).

\section{Preparation of PS substrates}

Flat PS substrates were prepared by spin coating (VTC-100, MTI Corporation, USA) with $12 \%(\mathrm{w} / \mathrm{v})$ PS in toluene. Fibrous surfaces were prepared by electrospinning $30 \%(\mathrm{w} / \mathrm{v})$ PS solution, where PS was dissolved in the solvent mixture of tetrahydrofuran (THF) and DMF in $3: 1 \mathrm{v} / \mathrm{v}$ ratio. An electrospinning apparatus (Spraybase ${ }^{\circledR}$, USA) was used to maintain a $10 \mathrm{~cm}$ distance between the collector and the spinning needle (22gauge), and fibers were spun horizontally toward the collector rotating at $100 \mathrm{rpm}$. The feeding rate of the PS solution was 2.0 $\mathrm{mL} \mathrm{h}^{-1}$, the applied voltage was $14 \mathrm{kV}$.

To increase the surface energy of polymer surfaces, both film and electrospun web were exposed to air plasma (PDC-32G, Harrick Plasma, USA), at approximately $100 \mathrm{mTorr}, 18 \mathrm{~W}$ for $3 \mathrm{~min}$. This plasma treatment also facilitated the later process of PFDTS chemical attachment by forming -OH groups on the surface. PFDTS (surface energy $\sim 17.2 \mathrm{mN} \mathrm{m}^{-1}$ ) was deposited by vapor coating on plasma-treated PS substrates. PFDTS was diluted to $5 \%(\mathrm{v} / \mathrm{v})$ in hexane, and the diluted solution was vaporized at approximately 100 Torr and $70{ }^{\circ} \mathrm{C}$ in a vacuum desiccator. ${ }^{26}$ Electrospun web topographies were observed using field-emission scanning electron microscope (FE-SEM) (Versa 3D Dual Beam, FEI, USA), with the prior sputter coating with Au/ Pd in $20 \mathrm{~nm}$ thickness (150TS, Quorum, UK).

\section{Analysis of wettability, surface energy, and zeta potential}

Static contact angle (CA) was measured for a $5 \pm 1 \mu \mathrm{L}$ liquid drop of distilled water (WA), PBS, and LB medium on PS substrates. Shedding angle (SA) was measured for a $10 \mu \mathrm{L}$ drop of water, PBS, and LB on the superhydrophobic PS electrospun web. Both CA and SA were measured by an optical tensiometer (Attension Theta, Biolin Scientific, USA).

Surface energy and its dispersive and polar components of PS substrates were estimated by using Wu's method, ${ }^{35}$ from the CA measurement of water and methylene iodide (MI). The polar $\left(\gamma_{\mathrm{L}}^{\mathrm{P}}\right)$ and dispersive $\left(\gamma_{\mathrm{L}}^{\mathrm{d}}\right)$ components, and the total surface 
tension $\left(\gamma_{\mathrm{L}}\right)$ for water and MI are as follows: for water, $\gamma_{\mathrm{L}}^{\mathrm{P}} 51.0$ $\mathrm{mN} \mathrm{m}^{-1}, \gamma_{\mathrm{L}}^{\mathrm{d}} 21.8 \mathrm{mN} \mathrm{m}^{-1}$, and $\gamma_{\mathrm{L}} 72.8 \mathrm{mN} \mathrm{m}^{-1}$; for MI, $\gamma_{\mathrm{L}}^{\mathrm{P}} 0 \mathrm{mN}$ $\mathrm{m}^{-1}, \gamma_{\mathrm{L}}^{\mathrm{d}} 50.8 \mathrm{mN} \mathrm{m}^{-1}$, and $\gamma_{\mathrm{L}} 50.8 \mathrm{mN} \mathrm{m}^{-1}$. $^{36}$

Zeta potential of PS and plasma-treated PS was measured using Zetasizer Nano ZSP (Malvern, USA). PS particles in powder form were prepared by electrospraying $10 \%(\mathrm{w} / \mathrm{v})$ PS solution, where PS was dissolved in THF and DMF in $3: 1 \mathrm{v} / \mathrm{v}$ ratio. The power-like PS particles were used as is and after plasma oxidation. The particles dispersed in distilled water were measured for zeta potential at $\mathrm{pH} 7$.

\section{Binding of bacteria to PS substrates}

GFP-ETEC culture was inoculated into $4.0 \mathrm{~mL} \mathrm{LB}$ and then incubated at $37^{\circ} \mathrm{C}$ to an $\mathrm{OD}_{600}$ of approximately 0.5 . The culture was diluted 1:3 in sterile PBS, placed on ice, and tested for adherence to PS substrates. For each PS film and electrospun substrate, discs (diameter $6 \mathrm{~mm}$ ) were cut to fill sequential wells of a 96-well plate. Diluted bacteria cultures $(100 \mu \mathrm{L})$ were added to each well, and PBS $(100 \mu \mathrm{L})$ was added as a negative control. The plate was incubated at $33^{\circ} \mathrm{C}$ for $1 \mathrm{~h}$.

Samples were sequentially washed up to four times with 100 $\mu \mathrm{L}$ of sterile PBS at $100 \mathrm{rpm}$ for 5 minutes. After washing, bacteria were fixed in $4 \%(\mathrm{w} / \mathrm{v})$ paraformaldehyde in PBS for $30 \mathrm{~min}$ at room temperature. Samples were rinsed with PBS and then placed onto slides for microscopic analysis. Samples were analyzed in duplicate using an Olympus IX73 inverted fluorescent microscope system with an excitation wavelength of $490 \mathrm{~nm}$ and an emission wavelength of $525 \mathrm{~nm}$. For each polymer substrate, two independent samples in $6 \mathrm{~mm}$ diameter discs were analyzed for twelve different locations of fluorescent areas (each in area of $110 \mu \mathrm{m} \times 120 \mu \mathrm{m}$ ) to quantify the area fraction adhered by $E$. coli using ImageJ.

\section{Results and discussion}

\section{Fabrication of PS substrates with varied surface wettability}

Electrospinning conditions were adjusted to create surfaces with different topographies, including particles and fibers. ${ }^{26}$ Among different topographies, a surface with wrinkled fibers was selected for this study, as it was durable enough to permit further experimentation. Substrate surface energy was increased by air plasma oxidation or decreased by vapor deposition of $1 \mathrm{H}, 1 \mathrm{H}, 2 \mathrm{H}, 2 \mathrm{H}$-perfluorodecyltrichlorosilane (PFDTS). Specimen codes for different substrates are listed in Table 1.

The oxidation by plasma treatment and fluorination by PFDTS vapor deposition have been shown in FTIR-ATR spectra

Table 1 Specimen codes

\begin{tabular}{ll}
\hline Code & Description \\
\hline$F$ & PS untreated spin-coated film \\
$F_{p}$ & PS film hydrophilized by air plasma treatment \\
$F_{f}$ & PS film treated hydrophobized by PFDTS vapor deposition \\
$E$ & PS untreated electrospun web with fibrous morphology \\
$E_{p}$ & PS fibrous web hydrophilized by air plasma treatment \\
$E_{f}$ & PS fibrous web hydrophobized by PFDTS vapor deposition
\end{tabular}

in previous work. ${ }^{26}$ Sample surface energies were calculated using Wu's method, ${ }^{35}$ by measuring CAs of water and methylene iodide (MI) on smooth surfaces of $\mathrm{F}, \mathrm{F}_{\mathrm{p}}$, and $\mathrm{F}_{\mathrm{f}}$ (Table 2). The surface energy of plasma-treated substrate was substantially increased, especially in the polar component. For the fluorinated substrate, the dispersive component was decreased considerably. PS surface topographies are shown in Fig. 2. Neither plasma treatment nor vapor deposition changed the overall morphology.

\section{Characterization of wettability}

PS substrate wettability against water (W), phosphate buffered saline (PBS), and Luria-Bertani (LB) medium was examined by measuring the static contact angles (CA) and shedding angles (SA) (Table 3). Surface roughness attributed to fibrous topography of electrospun webs can amplify the intrinsic wettability or antiwettability. ${ }^{34,37}$ PS is intrinsically hydrophobic with its Young's water contact angle (WCA) of $95^{\circ}$, and the roughness resulting from the fibrous structures increased the apparent WCA to $156^{\circ}$. For the plasma-treated substrates, the roughness of $\mathrm{E}_{\mathrm{p}}$ further enhanced hydrophilicity (WCA of $0^{\circ}$ ) as compared to the smooth $\mathrm{F}_{\mathrm{p}}$ substrate (WCA of $28^{\circ}$ ). Likewise, the fluorinated web $\mathrm{E}_{\mathrm{f}}$ exhibited increased hydrophobicity (WCA of $168^{\circ}$ ), while the fluorinated film $\mathrm{F}_{\mathrm{f}}$ showed moderate hydrophobicity (WCA of $115^{\circ}$ ). Thus, surface wettability can be altered by manipulating surface energy and topography (Table 3 ). PBS contact angles were similar to WCAs. The CA of LB medium was lower than that of water because LB contains tryptone that acts as a surfactant.

For a superhydrophobic surface with rough topography, a liquid drop rolls-off rather easily due to the reduced contact area between the adhered liquid and solid surface. ${ }^{26,38} \mathrm{E}_{\mathrm{f}}$ has a low shedding angle $\left(2.7^{\circ}\right.$ for water $)$ indicating the surface follows the Cassie-Baxter wetting state; on such a surface, liquid pinning does not occur, and the contact area between liquid and solid is reduced by the entrapped air. ${ }^{38}$ For a surface that follows the Cassie-Baxter wetting state, the solid area fraction $(f)$ can be roughly estimated using the Cassie-Baxter equation $^{34}$ below. To obtain $f$ in the equation, CA measured from a smooth film was used as the Young's CA $\left(\theta_{\mathrm{Y}}\right)$ and the CA measured from a rough electrospun substrates was used as the apparent $\mathrm{CA}\left(\theta_{\mathrm{CB}}\right)$.

Table 2 Contact angle of water and methylene iodide, and the estimated surface energy ${ }^{a}$

\begin{tabular}{|c|c|c|c|c|c|}
\hline \multirow[b]{2}{*}{ Substrate } & \multicolumn{2}{|c|}{$\begin{array}{l}\text { Contact angle } \\
\left({ }^{\circ}\right)\end{array}$} & \multicolumn{3}{|c|}{$\underline{\text { Surface energy }\left(\mathrm{mN} \mathrm{m}^{-1}\right)}$} \\
\hline & WA & MI & $\gamma_{\mathrm{S}}$ & $\gamma_{\mathrm{S}}^{\mathrm{d}}$ & $\gamma_{\mathrm{S}}^{\mathrm{p}}$ \\
\hline $\mathrm{F}$ & $95^{\circ}$ & $39^{\circ}$ & 43.2 & 40.6 & 2.6 \\
\hline $\mathrm{F}_{\mathrm{p}}$ & $28^{\circ}$ & $18^{\circ}$ & 79.6 & 48.3 & 31.3 \\
\hline $\mathrm{F}_{\mathrm{f}}$ & $115^{\circ}$ & $99^{\circ}$ & 15.8 & 13.6 & 2.2 \\
\hline
\end{tabular}

${ }^{a} \gamma_{\mathrm{S}}$, surface energy of solid substrate; $\gamma_{\mathrm{S}}^{\mathrm{d}}$, dispersive component of surface energy; $\gamma_{\mathrm{S}}^{\mathrm{P}}$, polar component of surface energy; $\gamma_{\mathrm{L}}$, surface tension of liquid; $\gamma_{\mathrm{L}}^{\mathrm{d}}$, dispersive component of surface tension of liquid; $\gamma_{\mathrm{S}}^{\mathrm{p}}$, polar component of surface tension of liquid. 

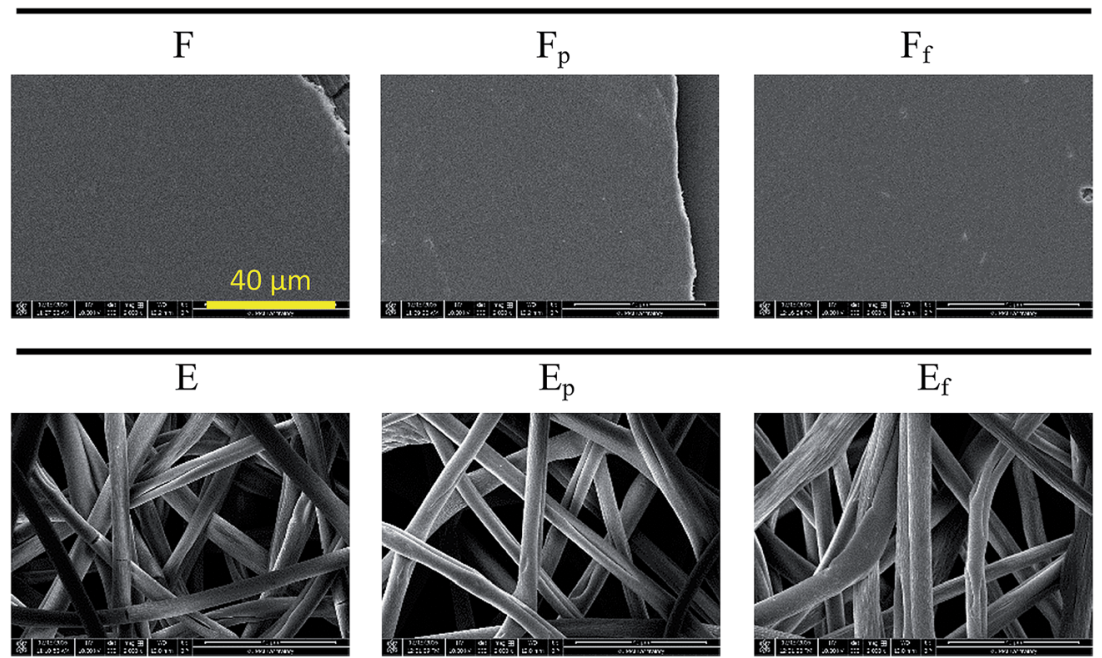

$\mathrm{E}_{\mathrm{p}}$

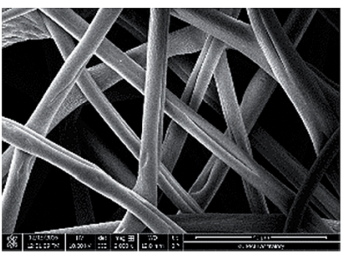

$\mathrm{E}_{\mathrm{f}}$

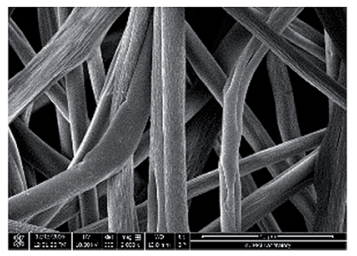

Fig. 2 Topography of PS substrates with varied treatments. A positive control substrate (cellulose filter paper) is added. All images are shown at the same magnification.

$\cos \theta_{\mathrm{CB}}=f\left(\cos \theta_{\mathrm{Y}}+1\right)-1($ Cassie-Baxter equation $)$

$\theta_{\mathrm{CB}}$ : apparent contact angle for Cassie-Baxter state, $\theta_{\mathrm{Y}}$ : Young's contact angle, contact angle at smooth surface, $f$ (solid area fraction): area fraction where liquid is in contact with a solid surface as opposed to air.

The calculated solid area fractions $(f)$ for $\mathrm{E}$ and $\mathrm{E}_{\mathrm{f}}$ surface in contact with water, PBS, and LB are shown in Table 3. It should be noted that estimation of solid area fractions $(f)$ for $\mathrm{E}$ may be less accurate than that for $\mathrm{E}_{\mathrm{f}}$. From a high shedding angle of $\mathrm{E}$ surface, it can be speculated that the liquid in contact with $\mathrm{E}$ may have intruded, at least partially, into the protrusions of surfaces. Thus, E surface may not fully satisfy the Cassie-Baxter's wetting state, giving less accurate estimation of $f . \mathrm{E}_{\mathrm{p}}$ surface with complete wetting is far from the Cassie-Baxter wetting state, thus the estimation of $f$ was not performed.

\section{Bacterial adhesion to PS substrates}

Surfaces with different wettability were exposed to $E$. coli in LB medium for $1 \mathrm{~h}$, and the adhered $E$. coli on substrates with and without washing are shown as green fluorescent areas in Fig. 3. Negative controls were added for all tested substrates and none

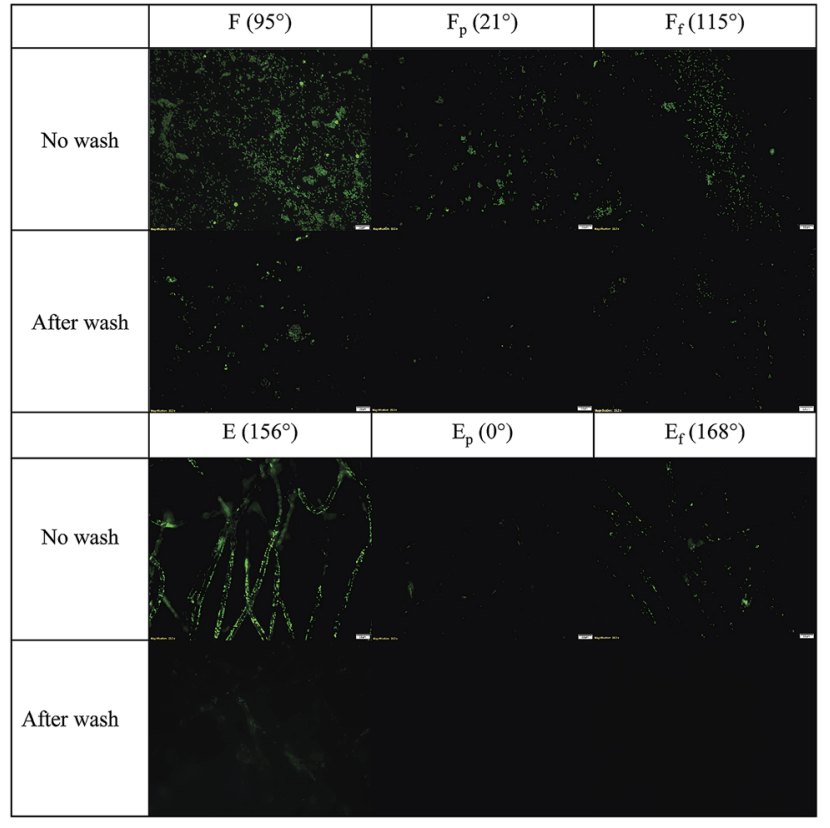

Fig. 3 Adhered E. coli on surfaces with and without PBS wash: embedded bar in the lower right is in $20 \mu \mathrm{m}$ length.

Table 3 Measurement of contact angle, shedding angle, solid area fraction, and roughness factor

\begin{tabular}{|c|c|c|c|c|c|c|c|}
\hline \multirow[t]{2}{*}{$\mathrm{CA}\left(^{\circ}\right)$} & Water & $95^{\circ}( \pm 1.1)$ & $28^{\circ}( \pm 2.0)$ & $115^{\circ}( \pm 1.6)$ & $156^{\circ}( \pm 2.1)$ & $0^{\circ}(\mathrm{NA})$ & $168^{\circ}( \pm 1.3)$ \\
\hline & PBS & $96^{\circ}( \pm 2.2)$ & $27^{\circ}( \pm 1.8)$ & $114^{\circ}( \pm 2.4)$ & $153^{\circ}( \pm 2.9)$ & $0^{\circ}(\mathrm{NA})$ & $169^{\circ}( \pm 3.4)$ \\
\hline \multirow[t]{3}{*}{ Shedding angle $\left(^{\circ}\right)$} & Water & $>90^{\circ}$ & & & $>90^{\circ}$ & & $2.7^{\circ}( \pm 0.24)$ \\
\hline & PBS & & & & & & $5.4^{\circ}( \pm 0.67)$ \\
\hline & LB & & & & & & $13.5^{\circ}( \pm 1.50)$ \\
\hline & LB & & & & 0.11 & & 0.09 \\
\hline
\end{tabular}




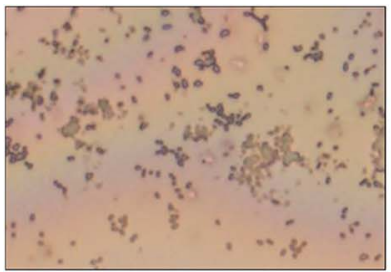

(a)

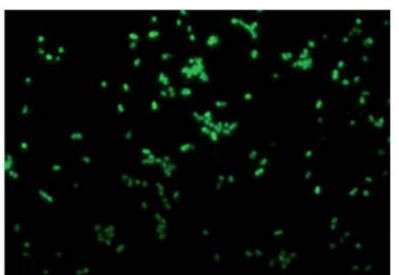

(b)

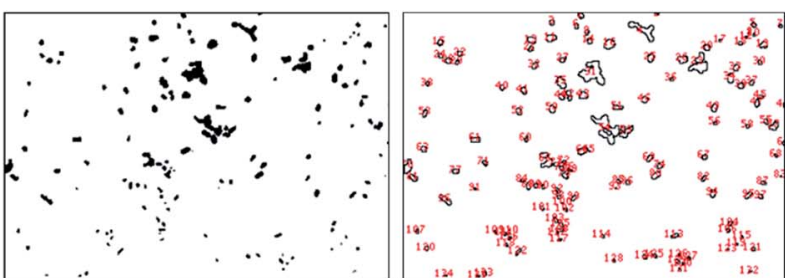

(c)

(d)

Fig. 4 Image analysis for measurement of an area fraction (\%) covered by E. coli: (a) bright field image, (b) fluorescence image, (c) black and white binary image produced using ImageJ, (d) boundary of bacteria-covered area analyzed from (b) using ImageJ.

of them showed fluorescence. On the smooth film surface (F), bacteria were distributed randomly, while they adhered along the fiber axis on E surface. Particularly, the protruded surface of fibers appeared to be the preferred site for bacterial attachment over the depression of surface.

A simple method for rough quantification of the adhered bacteria was developed (Fig. 4). The binding sites of bacteria on the bright field image (Fig. 4a) and the corresponding fluorescence image (Fig. 4b) match, demonstrating that the green fluorescence is true representation of adhered E. coli. The fluorescent area was converted to black and white binary image by adjusting the threshold of contrast (Fig. $4 \mathrm{~b}$ to c) using ImageJ, and the boundary of the binary image (Fig. 4d) was used for area calculations.

The area fraction covered by green fluorescence was used as a quantified representation of bacterial adhesion to substrates for further analysis in Fig. 5. In general, the untreated PS film and electrospun web displayed more E. coli adhered to surfaces, compared to plasma-treated or fluorinated surfaces. The polar component of surface energy for $\mathrm{F}$ and $\mathrm{E}$ (untreated PS) was measured to be $2.6 \mathrm{mN} \mathrm{m}^{-1}$ from the total surface energy of 43.2 $\mathrm{mN} \mathrm{m}{ }^{-1}$. Contradicting a previous report, ${ }^{12} \mathrm{~F}$ with a very low polar component of surface energy still had considerable bacterial adhesion. When PS surface energy was significantly lowered to $15.8 \mathrm{mN} \mathrm{m}^{-1}$ by fluorination $\left(\mathrm{F}_{\mathrm{f}}\right.$ and $\left.\mathrm{E}_{\mathrm{f}}\right)$, initial $E$. coli adherence was considerably lowered. Notably, $\mathrm{E}$ and $\mathrm{E}_{\mathrm{f}}$ surfaces whose WCA $>150^{\circ}$ showed a self-cleaning ability, in which the initially adhered bacteria were effectively removed after washing. This self-cleaning effect generally appears from superhydrophobic surfaces where the adhesion force between contaminating particles and solid surface is weakened due to reduced contact.

Area fractions adhered by $E$. coli as a function of WCA of surface are shown (Fig. 5b). The surface with WCA of $95^{\circ}$ gave the highest level of bacterial adhesion, and the adhesion decreased as the wettability becomes either higher $\left(\mathrm{F}_{\mathrm{p}} \sim 28^{\circ}\right)$ or lower $\left(F_{f} \sim 115^{\circ}\right)$. The results roughly correspond with earlier research $^{13}$ that showed that surfaces with a CA range of $54-130^{\circ}$ had higher bacterial adhesion by the promoted hydrophobic

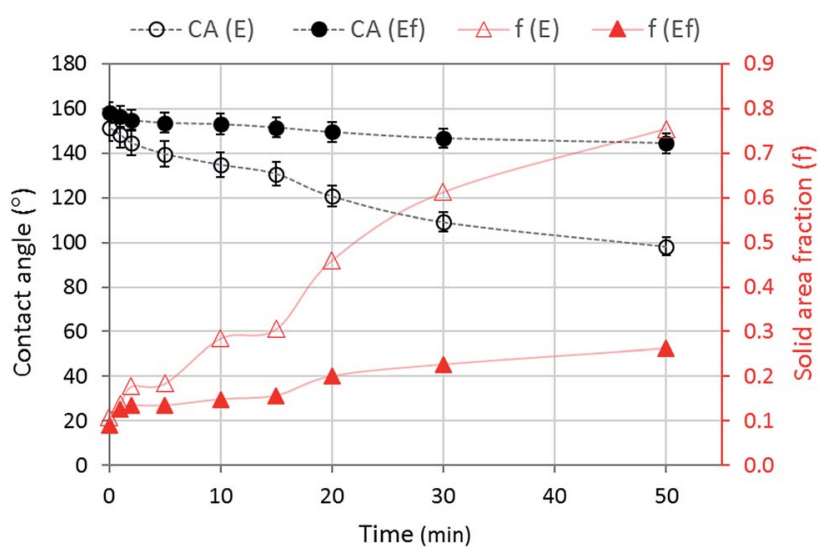

Fig. 6 LB contact angle (CA) and solid area fraction ( $f$ ) for $E$ and $E_{f}$ substrates as a function of time.
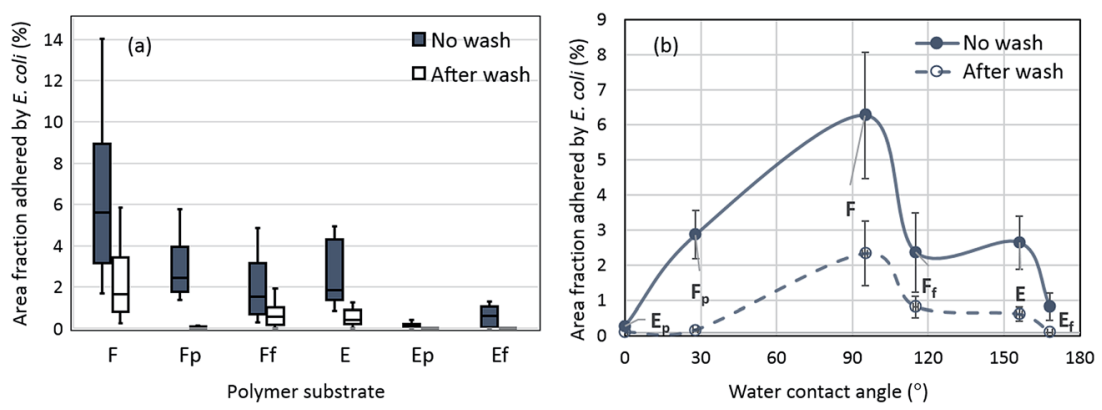

Fig. 5 Area fraction (\%) adhered by E. coli on PS surfaces with and without wash, (a) a whole data from twelve images are included; (b) average area fraction adhered by $E$. coli with respect to water contact angle of substrates (bars indicate standard deviations). * In Fig. $4(\mathrm{a})$, box represents the range of $25^{\text {th }}$ and $75^{\text {th }}$ percentile of raw data, the vertical bar shows the whole range of raw data. The horizontal bar in the box represents the median value. Statistical tests to show significant differences among samples are shown in Table S1. $\dagger$ Bacterial adhesion to substrates after washing is shown in Fig. S1. $\dagger$ 


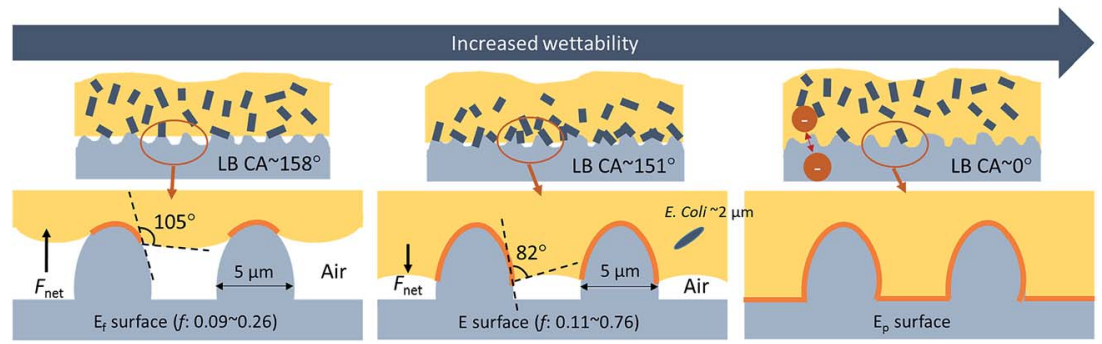

Fig. 7 Illustration of interactions at the interface between bacterial medium and fibrous rough surfaces.

interaction between the bacterial membrane and the solid surface. Adhesion of $\mathrm{E}\left(\mathrm{WCA} 156^{\circ}\right)$ was similar to those of $\mathrm{F}_{\mathrm{p}}$ and $\mathrm{F}_{\mathrm{f}}$, regardless of the lowered wettability for $\mathrm{E}$. The fibrous $\mathrm{E}$ surface would have provided a larger surface area for $E$. coli attachment, if the wetting of bacterial medium was not interfered. The superhydrophilic $\mathrm{E}_{\mathrm{p}}\left(\mathrm{WCA} 0^{\circ}\right.$ ) or superhydrophobic $\mathrm{E}_{\mathrm{f}}\left(\mathrm{WCA} 168^{\circ}\right)$ exhibited reduced bacterial adhesion.

For bacterial adhesion, the wettability of substrates to LB medium is important because the LB medium that contains $E$. coli should first wet the surface to allow the bacterial attachment to the substrate. If the wetting of bacterial medium is restrained due to the entrapped air of hydrophobic surfaces during an hour of contact, the adhesion of bacteria would be limited. ${ }^{25}$ To examine the maintenance of entrapped air during the exposure of fibrous surfaces to LB medium, CAs of LB medium (without E. coli) and the corresponding solid area fractions were measured with time (Fig. 6).

The LB contact angle was measured during $50 \mathrm{~min}$ of contact, because the size of a droplet was reduced to less than a half of the original droplet size due to evaporation in longer than $50 \mathrm{~min} . \mathrm{E}_{\mathrm{f}}$ maintained high CAs during $50 \mathrm{~min}$ while $\mathrm{E}$ decreased CAs considerably with time. High CAs of $\mathrm{E}_{\mathrm{f}}$ implies the maintenance of entrapped air at the interface during $50 \mathrm{~min}$, and this is somewhat evident by the low solid area fractions of $E_{\mathrm{f}}$ during this time (0.09-0.26). In contrast, the solid area fraction of $\mathrm{E}$ was substantially increased with time (0.110.76), indicating the intrusion of LB medium, at least partially, into protrusions on fibrous $\mathrm{E}$ surface. However, the calculation of solid fraction of $\mathrm{E}$ is not as accurate as that of $\mathrm{E}_{\mathrm{f}}$, as the perfect Cassie-Baxter wetting state is not met for the $\mathrm{E}$ surface.

The interfacial interactions for $\mathrm{E}$ and $\mathrm{E}_{\mathrm{f}}$ substrates are illustrated in Fig. 7. For both $\mathrm{E}$ and $\mathrm{E}_{\mathrm{f}}$ surfaces, complete wetting through the surface depressions, produced by fibers and fiber wrinkles, was prevented. Bacteria were most likely to adhere to protruded regions. The local contact angles of LB on $\mathrm{E}$ and $\mathrm{E}_{\mathrm{f}}$ at the protruded interface can be estimated as $82^{\circ}$ (from LB CA on F) and $105^{\circ}$ (from LB CA on $F_{f}$ ), respectively. On $E_{f}$ surface, the intrusion of liquid through the roughening structures would be hindered because of a high local CA $\left(105^{\circ}\right)$ at the protrusions, and the entrapped air between protrusions will be maintained. Due to the maintenance of low solid area fraction (0.09-0.26) on $\mathrm{E}_{\mathrm{f}}$ surface, bacterial adhesion was less for $\mathrm{E}_{\mathrm{f}}$ than E. Also, the adhered bacteria on $E_{f}$ were effectively removed by PBS wash, demonstrating the self-cleaning ability of $E_{\mathrm{f}}$ surface. This self-cleaning ability of superhydrophobic $E_{f}$ surface is attributed to the lowered adhesion force between bacteria and solid surface as a result of the reduced contact area. On E surface, the microscopic local CA at the protrusion is lower $\left(82^{\circ}\right)$, and the entrapped air would be reduced with time by the penetrated liquid. While a complete pinning could be prevented, the fibers on $\mathrm{E}$ would still provided a sufficient surface for bacterial attachment. Furthermore, hydrophobic interaction between bacterial membrane and hydrophobic surface would have promoted bacterial adhesion on E surface.

The superhydrophilic $\mathrm{E}_{\mathrm{p}}$ surface exhibited the least bacterial adhesion. For non-specific bacterial attachment, hydrophobicity and surface charge ${ }^{15}$ of bacteria are important parameters. The hydrophobic lipopolysaccharide (LPS) surface of Gram-negative bacteria accounts for the favored binding of $E$. coli to a hydrophobic surface over hydrophilic surface. ${ }^{39,40}$ Moreover, as E. coli has an overall negative charge, ${ }^{41}$ it may experience repulsive interactions with $\mathrm{E}_{\mathrm{p}}$, of which surface is oxidized by the air plasma treatment. The plasma-treated PS displayed a higher zeta potential $(-40 \mathrm{mV})$ compared to the untreated PS $(-8 \mathrm{mV})$. From this measurement, it was speculated that not only the demoted hydrophobic interaction but also the repulsive interaction between $\mathrm{E}_{\mathrm{p}}$ and E. coli resulted in the restricted adhesion of $E$. coli on $\mathrm{E}_{\mathrm{p}}$ surface, regardless of the increased wettability of $\mathrm{E}_{\mathrm{p}}$.

Multiple aspects of surface characteristics influence bacterial adhesion to material surfaces. Though surface energy is one of the important factors that causes hydrophobic interaction to promote bacterial adhesion, it is not the sole parameter of adhesion. A small-scale roughness on a superhydrophobic surface can hinder the contact of bacteria by the entrapped air, and a low work of adhesion on such a surface allows an easy removal of adhered bacteria by the self-cleaning effect. When the introduction of surface roughness promotes hydrophilicity, this can also hinder bacterial adhesion by discouraging the hydrophobic interaction and creating the substrate-bacteria repulsion.

\section{Conclusion}

The influence of effective surface area that allows initial bacterial adhesion was examined by analyzing the solid area fractions of substrates using the Cassie-Baxter equation. The selfcleaning ability of substrates against adhered bacteria was also examined in association with the solid area fraction. To understand the critical surface characteristics that are desirable 
for reducing bacterial binding, the adhesion of $E$. coli was examined with regards to material surface energy, roughness, wettability, and zeta potential. Moderate hydrophobicity with WCA of about $90^{\circ}$ produced the highest level of bacterial adhesion. A superhydrophilic substrate with a zeta potential of $-40 \mathrm{mV}$ exhibited limited bacterial binding, due to the demoted hydrophobic interaction and the repulsive interaction between $E$. coli and the substrate. On a superhydrophobic $\mathrm{E}_{\mathrm{f}}$ surface, the solid area fraction $(f)$ was reduced due to the entrapped air, and the bacterial adhesion to $\mathrm{E}_{\mathrm{f}}$ was lowered. Due to the reduced contact and the weakened adhesion of bacteria, $\mathrm{E}_{\mathrm{f}}$ surface exhibited self-cleaning ability against the bacteria, where the initially adhered bacteria were effectively removed with subsequent washing.

It can be concluded that an extremely hydrophobic or an extremely hydrophilic surface reduces $E$. coli adhesion. Careful surface design should be made not to promote the hydrophobic interaction with an enlarged surface area. The findings of this study provide information about the role of surface roughness on bacterial adhesion for polymeric surfaces with different surface energies. In this study, a Gram-negative, rod E. coli, was used as a model bacterium to screen the surface properties of polymeric materials to reduce bacterial adhesion. As bacterial shape and charge will affect adhesion, further study is suggested to include various bacteria with different properties and shapes, employing the developed analytical procedures in this study. Also, the study can expand to investigate the biofilm formation of polymeric surfaces.

\section{Acknowledgements}

This work was supported by 3M; Johnson Cancer Research Center; and College of Human Ecology from the Kansas State University.

\section{References}

1 L. Liu, B. Ercan, L. Sun, K. S. Ziemer and T. J. Webster, Understanding the Role of Polymer Surface Nanoscale Topography on Inhibiting Bacteria Adhesion and Growth, ACS Biomater. Sci. Eng., 2015, 2, 122-130.

2 N. MacCallum, C. Howell, P. Kim, D. Sun, R. Friedlander, J. Ranisau, O. Ahanotu, J. J. Lin, A. Vena, B. Hatton, T. Wong and J. Aizenberg, Liquid-infused Silicone as a Biofouling-free Medical Material, ACS Biomater. Sci. Eng., 2015, 1, 43-51.

3 X. Zhang, L. Wang and E. Levänen, Superhydrophobic Surfaces for the Reduction of Bacterial Adhesion, RSC Adv., 2013, 3, 12003-12020.

4 E. Fadeeva, V. K. Truong, M. Stiesch, B. N. Chichkov, R. J. Crawford, J. Wang and E. P. Ivanova, Bacterial Retention on Superhydrophobic Titanium Surfaces Fabricated by Femtosecond Laser Ablation, Langmuir, 2011, 27, 3012-3019.

5 M. Kargar, Y. Chang, H. K. Hoseinabad, A. Preden and W. A. Ducker, Colloidal Crystals Delay Formation of Early
Stage Bacterial Biofilms, ACS Biomater. Sci. Eng., 2016, 2, 1039-1048.

6 S. M. Kelleher, O. Habimana, J. Lawler, B. O'Reilly, S. Daniels, E. Casey and A. Cowley, Cicada Wing Surface Topography: An Investigation into the Bactericidal Properties of Nanostructural Features, ACS Appl. Mater. Interfaces, 2016, 8, 14966-14974.

7 K. Manabe, S. Nishizawa and S. Shiratori, Porous Surface Structure Fabricated by Breath Figures that Suppresses Pseudomonas aeruginosa Biofilm Formation, ACS Appl. Mater. Interfaces, 2013, 5, 11900-11905.

8 T. Liu, B. Yin, T. He, N. Guo, L. Dong and Y. Yin, Complementary Effects of Nanosilver and Superhydrophobic Coatings on the Prevention of Marine Bacterial Adhesion, ACS Appl. Mater. Interfaces, 2012, 4, 4683-4690.

9 M. Lorenzetti, I. Dogša, T. Stošicki, D. Stopar, M. Kalin, S. Kobe and S. Novak, The Influence of Surface Modification on Bacterial Adhesion to Titanium-based Substrates, ACS Appl. Mater. Interfaces, 2015, 7, 1644-1651.

$10 \mathrm{~K}$. Becker, Detachment Studies on Microfouling in Natural Biofilms on Substrata with Different Surface Tensions, Int. Biodeterior. Biodegrad., 1998, 41, 93-100.

11 C. I. Pereni, Q. Zhao, Y. Liu and E. Abel, Surface Free Energy Effect on Bacterial Retention, Colloids Surf., B, 2006, 48, 143147.

12 E. M. Harnett, J. Alderman and T. Wood, The Surface Energy of Various Biomaterials Coated with Adhesion Molecules Used in Cell Culture, Colloids Surf., B, 2007, 55, 90-97.

$13 \mathrm{X}$. Dou, D. Zhang, C. Feng and L. Jiang, Bioinspired Hierarchical Surface Structures with Tunable Wettability for Regulating Bacteria Adhesion, ACS Nano, 2015, 9, 10664-10672.

14 J. Li, T. Kleintschek, A. Rieder, Y. Cheng, T. Baumbach, U. Obst, T. Schwartz and P. A. Levkin, Hydrophobic LiquidInfused Porous Polymer Surfaces for Antibacterial Applications, ACS Appl. Mater. Interfaces, 2013, 5, 6704-6711.

15 D. Breite, M. Went, A. Prager and A. Schulze, Tailoring Membrane Surface Charges: A Novel Study on Electrostatic Interactions during Membrane Fouling, Polymers, 2015, 7, 2017-2030.

16 E. Preedy, S. Perni, D. Nipiĉ, K. Bohinc and P. Prokopovich, Surface Roughness Mediated Adhesion Forces Between Borosilicate Glass and Gram-positive Bacteria, Langmuir, 2014, 30, 9466-9476.

17 D. Perera-Costa, J. M. Bruque, M. L. González-Martín, A. C. Gómez-García and V. Vadillo-Rodríguez, Studying the Influence of Surface Topography on Bacterial Adhesion Using Spatially Organized Microtopographic Surface Patterns, Langmuir, 2014, 30, 4633-4641.

18 H. H. Tuson and D. B. Weibel, Bacteria-surface Interactions, Soft Matter, 2013, 9, 4368-4380.

19 M. Abrigo, P. Kingshott and S. L. McArthur, Electrospun Polystyrene Fiber Diameter Influencing Bacterial Attachment, Proliferation, and Growth, ACS Appl. Mater. Interfaces, 2015, 7, 7644-7652. 
20 C. Stallard, K. McDonnell, O. Onayemi, J. O'Gara and D. Dowling, Evaluation of Protein Adsorption on Atmospheric Plasma Deposited Coatings Exhibiting Superhydrophilic to Superhydrophobic Properties, Biointerphases, 2012, 7, 1-12.

21 J. H. Lee, H. B. Lee, J. W. Lee and G. Khang, Interaction of Different Types of Cells on Polymer Surfaces with Wettability Gradient, J. Colloid Interface Sci., 1998, 205, 323-330.

22 K. A. Poelstra, N. A. Barekzi, A. M. Rediske, A. G. Felts, J. B. Slunt and D. W. Grainger, Prophylactic Treatment of Gram-positive and Gram-negative Abdominal Implant Infections Using Locally Delivered Polyclonal Antibodies, $J$. Biomed. Mater. Res., 2002, 60, 206-215.

23 C. R. Crick, S. Ismail, J. Pratten and I. P. Parkin, An Investigation into Bacterial Attachment to an Elastomeric Superhydrophobic Surface Prepared via Aerosol Assisted Deposition, Thin Solid Films, 2011, 519, 3722-3727.

24 L. Shen, B. Wang, J. Wang, J. Fu, C. Picart and J. Ji, Asymmetric Free-standing Film with Multifunctional Antibacterial and Self-cleaning Properties, ACS Appl. Mater. Interfaces, 2012, 4, 4476-4483.

25 E. J. Falde, S. T. Yohe, Y. L. Colson and M. W. Grinstaff, Superhydrophobic Materials for Biomedical Applications, Biomaterials, 2016, 104, 87-103.

26 Y. Yuan, S. Choi and J. Kim, Analysis of Contact Area between Water and Irregular Fibrous Surface for Prediction of Wettability, RSC Adv., 2016, 6, 73313-73322.

27 M. Liu, S. Wang and L. Jiang, Bioinspired Multiscale Surfaces with Special Wettability, MRS Bull., 2013, 38, 375382.

28 T.-S. Wong, T. Sun, L. Feng and J. Aizenberg, Interfacial Materials with Special Wettability, MRS Bull., 2013, 38, 366-371.

29 A. K. Kota, W. Choi and A. Tuteja, Superomniphobic Surfaces: Design and Durability, MRS Bull., 2013, 38, 383390.

30 K. Liu, X. Yao and L. Jiang, Recent Developments in Boinspired Special Wettability, Chem. Soc. Rev., 2010, 39, 3243255.
31 R. Gristina, E. D'Aloia, G. S. Senesi, A. Milella, M. Nardulli, E. Sardella, P. Favia and R. d'Agostino, Increasing Cell Adhesion on Plasma Deposited Fluorocarbon Coatings by Changing the Surface Topography, J. Biomed. Mater. Res., Part B, 2009, 88, 139-149.

32 G. S. Senesi, E. D'Aloia, R. Gristina, P. Favia and R. d'Agostino, Surface Characterization of Plasma Deposited Nano-structured Fluorocarbon Coatings for Promoting In Vitro Cell Growth, Surf. Sci., 2007, 601, 10191025.

33 C. Sousa, D. Rodrigues, R. Oliveira, W. Song, J. Mano and J. Azeredo, Superhydrophobic Poly(L-lactic acid) Surface as Potential Bacterial Colonization Substrate, $A M B$ Express, 2011, 1, 1-9.

34 A. B. D. Cassie and S. Baxter, Wettability of Porous Surfaces, Trans. Faraday Soc., 1944, 40, 1905-1971.

$35 \mathrm{~S}$. Wu, Calculation of Interfacial Tension in Polymer Systems, J. Polym. Sci., Polym. Symp., 1971, 34, 19-30.

36 M. Zenkiewicz, Methods for the Calculation of Surface Free Energy of Solids, Journal of Achievements of Materials and Manufacturing Engineering, 2007, 24, 137-145.

37 R. N. Wenzel, Resistance of Solid Surfaces to Wetting by Water, Ind. Eng. Chem., 1936, 28, 988-994; A. B. D. Cassie and S. Baxter, Wettability of porous surfaces, Trans. Faraday Soc., 1944, 40, 1905-1971.

38 S. Park, J. Kim and C. H. Park, Analysis of the Wetting State of Super-repellent Fabrics with Liquids of Varying Surface Tension, RSC Adv., 2016, 6, 45884-45893.

39 J. H. Ryu, H. Kim, J. F. Frank and L. R. Beuchat, Attachment and Biofilm Formation on Stainless Steel by Escherichia coli O157:H7 as Affected by Curli Production, Lett. Appl. Microbiol., 2004, 39, 359-362.

40 B. Li and B. E. Logan, Bacterial Adhesion to Glass and Metaloxide Surfaces, Colloids Surf., B, 2004, 36, 81-90.

41 M. C. M. Van Loosdrecht, J. Lyklema, W. Norde, G. Scharaa and A. J. B. Zehnder, Electrophoretic Mobility and Hydrophobicity as a Measure to Predict the Initial Step of Bacterial Adhesion, Appl. Environ. Microbiol., 1987, 53, 1898-1900. 